\title{
Assessment of Food Safety Knowledge, Beliefs and Attitudes of Undergraduate Students at a Kenyan University: Results of an Online Survey
}

\author{
Samuel Imathiu
}

\begin{abstract}
A descriptive, cross-sectional survey was conducted using an online questionnaire to assess food safety knowledge, beliefs and attitudes among Jomo Kenyatta University of Agriculture and Technology undergraduate students. A total of 329 learners consented to participate in the study. The results revealed that overall respondents answered 46.2\% of the food safety knowledge questions correctly with similar scores across the five colleges (Agriculture and Natural Resources 47.4\%, Human Resource and Development 45.2\%, Engineering and Technology 46.7\%, Health Sciences 45.4\%, and Pure and Applied Sciences $46.5 \%$ ). Over $70 \%$ of respondents seemed to have positive beliefs and attitudes in most of the food safety beliefs and attitudes statements. A $\mathbf{7 8 . 7 \%}$ of respondents agreed or strongly agreed that food safety knowledge is important to them while $\mathbf{7 2 . 1 \%}$ and $\mathbf{7 7 . 7 \%}$ of the respondents were willing to learn how to make their food safe to eat, and how to prevent food poisoning from occurring respectively. Only a small proportion $(3.3 \%)$ of respondents felt that food safety was not their responsibility. The areas of most concern in food safety knowledge were in regard to crosscontamination and temperature control/food preservation. The proportions of correct responses on; "Imagine that your electricity went off and the meat, chicken, and/or seafood in your freezer thawed and felt warm. To prevent food poisoning, what should you do?", "A refrigerator has three shelves, on which shelf do you think raw meat should be placed?" and "What should be done if the leftovers are still not eaten completely?" were $7.3 \%, 24 \%$ and $24.6 \%$ respectively. These results show that students who participated in this study generally had unsatisfactory food safety knowledge regardless of their study category. There is therefore a need to offer food safety education/training to all learners, perhaps in short courses forms and not only on theory, but also on practical food safety aspects to bridge the food safety information gap.
\end{abstract}

Index Terms - Food handling, food hygiene, food safety, food safety knowledge, Kenya, university students.

\section{INTRODUCTION}

Foodborne illnesses, particularly those caused by pathogenic micro-organisms continue to pose public health challenges to both developed and developing countries, more so, to the later than the former. These diseases, which can be foodborne infections, foodborne intoxications or toxicoinfections have been known to cause morbidity and mortality at an alarming extent worldwide [1]. They have also been reported to influence the economies of developing and developed countries in a negative way, for example

Published on August 20, 2020.

Samuel Imathiu, Jomo Kenyatta University of Agriculture and Technology, Kenya.

(e-mail: samuel.imathiu@jkuat.ac.ke) through loss of working hours due to disease and, often, expensive treatments [2]. It is for this reason that most governments have put up or are putting up measures in place through special regulatory authorities in their countries to protect their consumers' health [3]. Food safety, which is defined as the degree of confidence that food (and drinks) will not cause an adverse effect to the consumer when it is prepared, served and consumed according to its intended use [4], is everyone's responsibility. This means that strict care to prevent pathogen contamination, survival and growth from farm-to-fork would be sufficient to ensure provision and consumption of safe food. For this to happen, all practitioners along the food supply chain including farmers, retailers, wholesalers, processors, distributors and consumers among others should in one way or another contribute to safe food production and provision.

A wide range of factors have been identified as contributors to the occurrence of microbial foodborne diseases. Published epidemiological data from various parts of the world indicates that a significant percentage of foodborne ailments are traceable to inadequate food preparation and unhygienic practices in consumers' homes [5], often as a result of lack of food safety knowledge, inappropriate beliefs and attitudes, and ignorance. This includes inappropriate handling of foods by the consumers during preparation, serving and storage [6, 7]. In the EU for example, it was reported that $36.4 \%$ of the microbial foodborne illnesses were caused by inappropriate food handling practices at homes, followed by $20.6 \%$ in food service establishments and $5.5 \%$ in schools including kindergartens [8]. In China, $50.6 \%$ of the reported microbial foodborne illness cases and $85.5 \%$ of the deaths were attributed to food that was prepared at home during the year of 2014 [9]. Several food safety studies have demonstrated that mishandling of foods results because consumers have little or no knowledge about appropriate safe food handling practices [10].

According to Byrd-Bredbenner et al [11], mishandling of food is common in some consumer groups than in others, especially young adults. In fact Majowicz et al. [12] have reported the youth being a unique target for food safety training as a result of their poor knowledge in food safety. It is not well known why certain consumer groups tend to have riskier food handling behaviors than others. Some researchers such as Altekruse et al. [13] hypothesized that this kind of risky behavior may be due to lack of basic food safety education or even lack of food handling experience among these groups. Other hypothesized reasons include the increasing trend in the consumption of ready-to-eat foods 
bought and consumed outside homes (consumers have no opportunity to learn food handling and preparation) [14], decreasing and/or non-existing food preparation and handling classes/lessons in schools [11], and lack of previous employment that involved food preparation/handling and/or serving [10].

Studies in food safety knowledge, behaviors and practices have been carried out among young adults in many parts of the world and the findings have shown that this particular group of consumers are engaging in food safety behaviors that put their health and those of others at risk of microbial foodborne illnesses [11, 10, 9, 3]. Previous studies have reported young adults aged between 18 and 29 years, which is generally a university age bracket, to most likely consume unsafe foods [15] probably because they are more confident about their food safety preparation methods and they are more learned [16]. A study carried out in Saudi Arabia indicated that $50 \%$ of the college students consumed raw eggs and 34\% thought that there were no risks associated with eating cooked food kept at room temperature for a day [17] in a study where students averaged $75 \%$ correct answers to 15 food safety knowledge questions. Knowledge in food safety also tends to be limited among young adults in other countries. The mean right answers to food safety knowledge questions among the US college students were reported to be low (49\%) [18]. Similar studies carried out in Lebanon did not also give impressive results with the students averaging 54\% of the correct answers [19]. One of the ways suggested to prevent and/or control microbial foodborne illnesses is educating consumers on safe food handling and good hygienic practices [20]. Although efforts should be put to promote food hygiene and safety education, very little is currently known about young adults' food hygiene and safety knowledge. Designing an intervention targeted at improving food handling knowledge of young adults, particularly in institutions of higher learning should be based on an actual understanding of food handlers' knowledge and experiences [9].

Currently, there is limited understanding of food safety knowledge among young adults in Kenya, and in particular, no food safety knowledge studies have been carried out among university or college students. Young adults have generally been found to have poorer food safety knowledge compared to older adults [21]. The objective of this study was to assess the food safety knowledge, beliefs and attitudes of undergraduate students at Jomo Kenyatta University of Agriculture and Technology (JKUAT) in Kenya, including demographic factors associated with food safety knowledge, in order to identify areas for, and groups that may benefit from possible food safety education. This information can be used to develop food safety trainings/programs for JKUAT students and possibly extend the same to other learning institutions.

\section{MAterials AND Methods}

\section{A. Design of online survey questionnaire}

The questionnaire used in this study was designed in Google forms (an application in Google Drive office suite). The questionnaire comprised of thirty six questions grouped into three main categories; demographic information (9 questions), food safety knowledge (12 questions), and food safety beliefs and attitudes (15 questions). The survey questionnaire was developed on the basis of, and by selecting pre-existing questions from previously validated and used questionnaires [9]-[12]. Questions regarding demographic information sought for information such as age, gender, mode of study and ability to cook, among others. The questionnaire section dealing with food safety knowledge sought to understand respondents' knowledge in regard to pathogenic microorganisms, cross-contamination, hygiene practices, and temperature control/food preservation. Food safety beliefs and attitudes questions, where attitude according to Sharif and Al-Malki [17] is "a complex mental state involving beliefs, feelings, values and dispositions to act in certain ways" were meant to determine undergraduate students as food handlers' attitude and understanding about food safety, and prevention of foodborne illnesses. The type and number of questions in each category was chosen in a manner to obtain the most relevant information sought for in this study at a respondent time not exceeding thirty minutes. The questionnaire was therefore pre-tested and relevant amendments made prior to commencement of the study. In the first page of the questionnaire, participants were provided with the details about the study including how collected data would be used and their right to opt out of it at any time. They were also required to give informed consent before proceeding with the survey. No incentives were promised or given to the study participants upon agreeing and/or completing the online questionnaire.

\section{B. Study participants and questionnaire administration}

Persons taking part in this study were main campus undergraduate students at Jomo Kenyatta University of Agriculture and Technology with a population of approximately 20000 students spread across five colleges (Health Sciences, Agriculture and Natural Resources, Engineering and Technology, Human Resource and Development, and Pure and Applied Sciences). Once the survey design and piloting of the online survey was complete, the investigator sought permission with the university's ICT directorate to have willing students participate in the study by sending the survey in form of a Google document link to each individual undergraduate student's email address. The descriptive, cross-sectional survey was conducted between March 15 to September 6, 2018. An email reminder to the willing participant to complete the survey was sent twice through the ICT directorate before the end of the study.

\section{Data analysis}

The Google form data was exported to Microsoft Excel 2010 spreadsheet after the end of the survey. Statistical descriptive data analysis was carried out using Microsoft Excel 2010 and results summarized in tables and figures.

\section{RESUlts AND DisCUSSION}

\section{A. Demographic characteristics of respondents}

The total number of participants whose responses were received by the close of the survey period was 329. Most of the respondents were aged between 20 and 22 years and 
were male (Table 1). This is not a surprising observation because, despite the small sample size in relation to the campus student population, most of the learners are male and within the age bracket observed. In a study investigating Saudi Arabian university students' food safety concerns, knowledge and practices, Al-Shabib et al. [3] reported similar observations in regard to student participants' age and gender. The authors reported a mean age of majority of respondents being 21.1 years and male respondents exceeding female respondents $(53.4 \%$ and $46.6 \%$ respectively). Similar results in regard to age of university student participants have been reported by Stratev et al. [22]. However, these authors' findings on the proportion of respondents' participation in relation to gender differ with this study's findings. Stratev et al. [22] reported that majority of the respondents were females $(55.6 \%)$ compared to males $(44.4 \%)$. Other authors that have reported more university female respondents than male include Hassan and Dimassi [19], Takeda et al. [23], Ovca et al. [24] and Lazou et al. [25]. The dissimilarities in these findings may be attributed to differences in population composition in terms of overall male to female population numbers which is institution dependent.

TABLE 1: DEMOGRAPHIC CHARACTERISTICS OF STUDY RESPONDENTS TO JKUAT FOOD SAFETY KNOWLEDGE, BELIEFS AND ATTITUDES QUESTIONNAIRE SURVEY. FIGURES IN BRACKETS REPRESENT NUMBER OF RESPONDENTS

\begin{tabular}{|c|c|}
\hline Demographic characteristic & $\begin{array}{c}\text { Proportion and } \\
\text { number of respondents }\end{array}$ \\
\hline $\begin{array}{l}\text { Gender } \\
\text { Male } \\
\text { Female } \\
\text { Other }\end{array}$ & $\begin{array}{c}\% \quad(\mathbf{n}) \\
65.3(215) \\
34.0(112) \\
0.6(2)\end{array}$ \\
\hline $\begin{array}{l}\text { Age } \\
18 \text { years or younger } \\
19 \\
20 \\
21 \\
22 \\
23 \text { years or older }\end{array}$ & $\begin{array}{l}2.7(9) \\
10.0(33) \\
22.2(73) \\
22.5(74) \\
20.1(66) \\
22.5(72)\end{array}$ \\
\hline $\begin{array}{l}\text { College } \\
\text { Agriculture and Natural Resources } \\
\text { Health Sciences } \\
\text { Engineering and Technology } \\
\text { Pure and Applied Sciences } \\
\text { Human Resource and Development }\end{array}$ & $\begin{array}{l}23.7(78) \\
10.0(33) \\
21.6(71) \\
26.7(88) \\
17.9(59)\end{array}$ \\
\hline $\begin{array}{l}\text { Mode of study } \\
\text { Regular student } \\
\text { Parallel/module II student }\end{array}$ & $\begin{array}{l}69.9(230) \\
31.1(99)\end{array}$ \\
\hline $\begin{array}{l}\text { Living arrangements } \\
\text { On campus } \\
\text { Off campus } \\
\text { At home }\end{array}$ & $\begin{array}{l}19.4(64) \\
66.3(218) \\
14.3(47)\end{array}$ \\
\hline $\begin{array}{l}\text { Cooking habits } \\
\text { At least once a day } \\
\text { A few times a week } \\
\text { A few times a month } \\
\text { A few times a year } \\
\text { Never }\end{array}$ & $\begin{array}{c}55.6(183) \\
27.1(89) \\
9.7(32) \\
5.5(18) \\
2.1(7)\end{array}$ \\
\hline
\end{tabular}

Most of the survey participants, constituting slightly above $25 \%$ of all respondents came from the School of Pure and Applied Sciences which is among the largest at the university. Majority of the student participants (69.9\%) pursued their programs on a regular mode of study at the university with the remaining proportion $(30.1 \%)$ studying under parallel, otherwise referred to as module II mode of study. Students pursuing their studies on regular mode are sponsored by the government while those studying on a parallel mode are self-sponsored. The largest proportion of the respondents lived off campus $(66.3 \%)$ while those living on campus, and those commuting from their homes to the university to study constituted $19.4 \%$ and $14.3 \%$ of total number of respondents respectively. This observation is an expected one since Kenyan universities in general admits many students with limited accommodation facilities on campus leaving learners with no other option other than commuting to the university from outside. Similar findings, though in a different study environment, have been reported by Courtney et al. [10] who were investigating undergraduate students' knowledge of food safety at a Canadian university. The authors reported that $64.8 \%$ of the respondents lived off campus while $17.5 \%$ lived at home out of a sample size of 480 participants.

Majority of the survey participants $(99.4 \%)$ could cook their own foods from raw materials although this ability to cook differed with the type of food in question. Many students may not have been preparing/cooking their own meals before joining the university which changes immediately they do as majority usually live away from their families. Only a small percentage $(1.8 \%)$ of those who were capable of making their own meals could only be able to do so while following instructions on a food label, highlighting the importance of the food label in food preparation and food safety practices. Over half $(55.6 \%)$ of the survey participants reported cooking their own meals at least once in a day with just $2.1 \%$ never attempting to cook for themselves. This relatively high number of respondents reporting to cook for themselves irrespective of the frequency of cooking is important in respect to food safety knowledge and practices. If this large proportion of learners does not adhere to food safety procedures during food preparation, then there is the likelihood of the food they handle presenting health risks to themselves and other consumers, and the opposite is true. At the time of the survey, $14 \%$ of the respondents were working or volunteering in establishments in which food preparation was carried out e.g. restaurants, daycare centers, nursing homes and hospitals. Courtney et al. [10] reported that $26.7 \%$ of student survey participants in a Canadian study either worked or volunteered in establishment in which food preparation was carried out (hospital, retirement homes, restaurant, deli, daycare centres, etc). Out of the $14 \%$ of the respondents who were working or volunteering, only $15.5 \%$ of them were involved in some form of food preparation. This group, however small it is, is critical along the food supply chain in regard to food safety. Safe food handling for the public, especially those at high risk such as the elderly, the pregnant and the young children calls for stringent adherence to food safety procedures.

\section{B. Overall food safety knowledge of respondents}

It is the responsibility of everyone, from farm-to-fork, to ensure that the food produced does not pose any health risks to the consumers along the supply chain. With this in mind, it expected that along this food supply chain every individual has at least some basic knowledge on food hygiene and safety to prevent occurrence of foodborne 
illnesses. This knowledge is often assumed obvious, acquired through observation and/or through learning in some form of training from basic education to advanced training. It is in this regard that learners at institutions of higher learning are assumed to have some knowledge of basic food safety knowledge.

This survey finding yielded some interesting results about the university students in regard to food safety knowledge. On average, the respondents answered $46.2 \%$ of the food safety knowledge questions correctly suggesting majority's poor understanding of food hygiene and safety principles. This poor understanding of basic food safety knowledge among the learners may lead to increased risks to foodborne illnesses, particularly because majority of them reported being involved in some form of food preparation, especially for themselves (Table 1). Similar studies assessing students' food safety knowledge have been reported elsewhere. In an investigation assessing food safety and handling knowledge and practices of Lebanese university students, Hassan and Dimassi [19] reported an average correct score of $53.6 \%$ while findings in a Greek and Jordanian universities reported an average correct score of 50\% [25] and $33.9 \%$ [26] respectively. A similar, more recent study carried out in Sweden showed that $63.4 \%$ of student respondents correctly answered food safety knowledge questions [27]. These differences may be attributed to differing levels of food safety knowledge and experiences among the sampled student populations from each institution.

Table 2 summarizes the proportions of learners choosing the correct answer for a given food safety knowledge question, and the most frequently picked wrong answer. Out of twelve food safety knowledge questions, it is only in less than half of them (five questions, representing $41.7 \%$ of the questions) that an above average number of respondents got correct i.e. Q1, Q2, Q3, Q7 and Q8 (Table 2). This indicates a huge knowledge gap in food safety understanding among these learners that needs to be addressed. The food safety knowledge questions whose correct answer was most frequently selected $(92.4 \%)$ was Q1 which sought to understand whether or not learners knew what microorganisms were. A similar result where $96.8 \%$ of university student respondents picked the correct answer to a similar question was reported by Courtney et al. [10] in a study investigating food safety knowledge of undergraduate students at a Canadian university. This is an important basic question where all respondents were expected to get it right as they ought to have come across this term in their learning journeys including at basic level education. It would be difficult to understand the deleterious effects of microorganisms e.g. foodborne diseases (and food spoilage), their benefits (e.g. food bioprocessing), and how to prevent/control and/or promote their growth without first understanding what they are as a prerequisite.

TABLE 2. PROPORTION OF JKUAT UNDERGRADUATE STUDENT PARTICIPANTS ( $\mathrm{N}=329)$ CHOOSING THE CORRECT ANSWER AND THE MOST COMMONLY PICKED WRONG ANSWER TO FOOD SAFETY KNOWLEDGE QUESTIONS

\begin{tabular}{|c|c|c|c|c|}
\hline \multirow[b]{2}{*}{ Food safety knowledge question } & \multicolumn{4}{|c|}{ Proportion of students choosing a given answer } \\
\hline & Right answer & $\%$ & $\begin{array}{c}\begin{array}{c}\text { Most frequently chosen wrong } \\
\text { answer }\end{array} \\
\end{array}$ & $\%$ \\
\hline Q1. What are microorganisms? & $\begin{array}{l}\text { Small living things that are too } \\
\text { small to be seen with our eyes }\end{array}$ & 92.4 & $\begin{array}{l}\text { Poisons that can contaminate our } \\
\text { food and water }\end{array}$ & 7.6 \\
\hline Q2. How should chunks of raw meat be stored? & $\begin{array}{l}\text { Slice into smaller pieces, seal and } \\
\text { store them in refrigerator }\end{array}$ & 71.1 & Store it directly in the refrigerator & 12.2 \\
\hline $\begin{array}{l}\text { Q3. When is the best time to purchase frozen food } \\
\text { when shopping? }\end{array}$ & At the end of shopping time & 68.1 & I do not know & 12.2 \\
\hline $\begin{array}{l}\text { Q4. Of the following, which is the least safe way to } \\
\text { thaw raw meat? }\end{array}$ & Thaw slowly on chopping board & 29.5 & $\begin{array}{l}\text { Thaw in cold water in sealed } \\
\text { package }\end{array}$ & 30.1 \\
\hline $\begin{array}{l}\text { Q5. What should be done if the leftovers are still not } \\
\text { eaten completely? }\end{array}$ & Discard them immediately & 24.6 & $\begin{array}{l}\text { Put in the refrigerator immediately } \\
\text { and reheat before consuming }\end{array}$ & 66.3 \\
\hline $\begin{array}{l}\text { Q6. A refrigerator has three shelves, on which shelf } \\
\text { do you think raw meat should be placed? }\end{array}$ & Bottom shelf & 24 & Top shelf & 55 \\
\hline $\begin{array}{l}\text { Q7. What is the recommended temperature for } \\
\text { fridges? }\end{array}$ & $4^{\circ} \mathrm{C}$ & 55 & Don't know & 26.4 \\
\hline $\begin{array}{l}\text { Q8. To prevent food poisoning, how often should the } \\
\text { kitchen sink drain in your home be sanitized? }\end{array}$ & Daily & 62.6 & Weekly & 24.6 \\
\hline $\begin{array}{l}\text { Q9. Which is the most hygienic way to wash your } \\
\text { hands? }\end{array}$ & $\begin{array}{l}\text { Run water, moisten hands, apply } \\
\text { soap, rub hands together for } 20 \\
\text { seconds, rinse hands, dry hands }\end{array}$ & 38.6 & $\begin{array}{l}\text { Run water, moisten hands, apply } \\
\text { sanitizer, rub hands together for } 20 \\
\text { seconds, rinse hands, dry hands, rub } \\
\text { on antiseptic hand lotion }\end{array}$ & 33.4 \\
\hline $\begin{array}{l}\text { Q10. If you have a wound on the back of your hand, } \\
\text { should you prepare food for other people? }\end{array}$ & $\begin{array}{l}\text { Yes, if you bandage the wound } \\
\text { and wear a glove. }\end{array}$ & 44.4 & $\begin{array}{l}\text { No, you should not prepare food } \\
\text { until the wound heals. }\end{array}$ & 39.5 \\
\hline $\begin{array}{l}\text { Q11. Imagine that your electricity went off and the } \\
\text { meat, chicken, and/or seafood in your freezer thawed } \\
\text { and felt warm. To prevent food poisoning, what } \\
\text { should you do? }\end{array}$ & Throw them away & 7.3 & Cook them right away & 38.3 \\
\hline $\begin{array}{l}\text { Q12. If a family member is going to be several hours } \\
\text { late for a hot meal, how should you store the meal to } \\
\text { keep it safe until this person is ready to eat it? }\end{array}$ & $\begin{array}{l}\text { Store it in the refrigerator and } \\
\text { reheat it when the person is ready } \\
\text { to eat it }\end{array}$ & 32.2 & $\begin{array}{l}\text { Store it in a warm oven until the } \\
\text { person is ready to eat it }\end{array}$ & 50.2 \\
\hline
\end{tabular}

Over $60 \%$ of respondents knew; how to store chunks of raw meat $(71.1 \%)$, best time to purchase frozen foods during shopping $(68.1 \%)$ and the frequency of sanitizing kitchen sink $(66.2 \%)$ to ensure food safety. It is recommended that frozen foods are purchased last during shopping to limit thawing by the time the shopper gets home to curtail the possibility of food poisoning, especially through crosscontamination through juice leaks. Similar results to this study's finding in this regard were reported by Hassan and Dimassi [19] in a Lebanese university (60\%) and Osaili et al. [26] in a Jordanian university (74\%). In respect to frequency of kitchen sink drain sanitization, Lazou et al. 
[25] reported that $21 \%$ of respondents chose the correct answer in a Greek study while Hassan and Dimassi [19] reported that $52 \%$ of respondents picked the correct answer in a Lebanese study.

Surprisingly, more than half of the respondents picked wrong answers to seven of the twelve food safety knowledge questions representing a proportion of $58.3 \%$. The worst performed was Q11 ('Imagine that your electricity went off and the meat, chicken, and/or seafood in your freezer thawed and felt warm. To prevent food poisoning, what should you do?'), where only $7.3 \%$ of respondents selected the correct answer. In a similar question, in contrast, $20.1 \%$ of student respondents in a Jordan university study $(\mathrm{n}=867)$ selected the correct answer [26] while $56 \%$ of student respondents in a Canadian university [10] and $31.6 \%$ in a Greek study [25] respectively selected the correct answer. Only less than a third of the respondents knew the safest way to defrost raw meat (29.5\%), handle food leftovers $(24.6 \%)$, best shelf in a refrigerator to store raw meat $(24 \%)$ and the best storage condition for hot prepared meal until it is eaten $(32.2 \%)$. This indicates respondents' poor understanding of food storage/preservation and temperature control. These are definitely knowledge gaps that need to be addressed through training. Previous studies have reported incorrect food handling and storage among young adults [11], and results from this study are not surprising.

The question which had most of the respondents give the wrong answer (most frequently chosen wrong answer) was in regard to what should be done in case leftovers were still not eaten completely. A large number of respondents $(66.3 \%)$ thought that storing leftovers not eaten completely should be refrigerated again immediately and reheated before consuming. This is a wrong and risky food safety behavior which constitutes improper handling of food leftovers which according to USDA [28], can lead to foodborne diseases. Fifty five percent of the participant thought that raw meat should be stored at the top shelf of a refrigerator which is wrong as it may lead to crosscontamination in case there is dripping of the juices. Slightly less than half of the respondents $(45 \%)$ either did not know the recommended refrigerator temperature or they incorrectly selected the wrong answer. This is not a surprising observation as previous other studies have reported even higher proportions of survey participants not conversant with recommended refrigeration and freezer temperatures. For example, Ferk et al. [29] reported that over half of respondents $(52 \%)$ did not know the correct refrigeration temperature. In similar studies in Lebanon [19], Jordan [26] and Greece [25], authors reported only 53\%, $34 \%$ and $44 \%$ of university student respondents respectively correctly picking the correct answer. It is important to know the refrigeration temperature as foods stored at a higher temperature other than the recommended temperature does not only readily spoil but can also be potentially hazardous to the consumers.

Hand washing is an integral part of good food hygiene and safety practices. In this study, a mere $38.6 \%$ of respondents selected the correct hand washing procedure. This finding is in contrast to an observation made by Courtney et al. [10] where a larger proportion of student respondents $(71.5 \%)$ selected the correct answer in a Canadian study. Other studies where more student respondents selected the correct procedure of hand washing compared to this study findings include investigations by Green and Knechtges [18] (55\%) and Osaili et al. [26] $(51 \%)$. The most frequently selected wrong answer to this question (33.4\%) involved application of a sanitizer after moistening hands with water. This may suggest that many students do not know the difference between sanitizers and soap, and/or the difference between hand washing and hand sanitizing. This observation highlights the need to promote good hand hygiene practices among JKUAT students, as a link has been established between infectious diseases, absence from class and increased hospital visits with poor hand hygiene among university students [30]. Learners' proper hand hygiene practices should be encouraged at the university perhaps through hand hygiene education/training or demonstrations to safeguard students' health.

To a question 'If a family member is going to be several hours late for a hot meal, how should you store the meal to keep it safe until this person is ready to eat it?', only $32.2 \%$ of the participants selected the correct answer with slightly more than half $(50.2 \%)$ picking the most frequent wrong answer (Table 2). Similar studies in Lebanon [19], Jordan [26] and Greece [25] reported that 29\%, 50\% and $28 \%$ of university student respondents respectively knew that cooked food, if not immediately consumed needed to be immediately refrigerated until the person is ready to eat it. Courtney et al. [10] reported a higher number of participants picking the correct answer to the same question $(65.7 \%)$. These dissimilarities may be due to varying levels of food safety knowledge, awareness and experiences among respondents from these different universities. Over a third of the participants $(39.5 \%)$ thought that it was wrong for a person with a wound on their hand to prepare food for other people, which was the most frequently chosen wrong answer. On the other hand, less than half of the participants (44.4\%) chose the correct answer, that a person with a wound on their hand can in fact prepare food for other people if they bandaged the wound and wore gloves. Lazou et al. [25] reported a lesser proportion of the respondents (19.6\%) choosing the correct answer to the same question in a similar study in Greece. Likewise, Osaili et al. [26] reported that only $23 \%$ of the respondents chose the correct answer to the same question in a Jordanian university. Osaili et al [26] investigation, however, focused on female students only. Hands are the main vehicles of transmitting pathogenic microorganisms to foods and presence of wounds, especially septic ones make the situation worse since microbes readily multiply in such sites. Bandaging and wearing gloves creates an immediate barrier between the hand and the food and/or any other food contact surface, reducing the possibility of microbial food contamination.

\section{Responses on food safety knowledge of five college categories}

As observed previously, the overall students' knowledge on food safety was generally unsatisfactory across all the five categories of learners where a similar average correct answer score was obtained across all study categories (Agriculture and Natural Resources 47.4\%, Human 
Resource and Development 45.2\%, Engineering and Technology 46.7\%, Health Sciences $45.4 \%$, and Pure and Applied Sciences $46.5 \%$ ) (Table 3). In a similar study, Luo et al. [31] noted that three categories of learners (nursing, education and medical college students) in China had inadequate food safety knowledge. It is only in four out of twelve questions that the correct response percentages were either $50 \%$ or above across all colleges (Table 3). These questions were 'What are microorganisms?', 'How should chunks of raw meat be stored?', 'When is the best time to purchase frozen food when shopping?', and 'To prevent food poisoning, how often should the kitchen sink drain in your home be sanitized?' On average, students in the college of Health Sciences performed better than the rest of the groups as they scored less than 50\% (comprising 50\% of food safety knowledge questions) in fewer questions than the rest of the groups. The college of Human Resource and Development performed the worst in food safety knowledge as they recorded on average less than $50 \%$ in most of the questions (comprising $66.7 \%$ of food safety knowledge questions). This general observation is not surprising because the college of Human Resource and Development offers social science based programs and one would not expect them to be offered any food safety related courses which are science based. Therefore, assuming they had no prior food safety knowledge before joining the university, their responses in this regard are not entirely surprising. On the contrary, learners in the college of Health Sciences are expected to have more knowledge in food safety related topics by the virtue of studying a health related program bearing in mind that health and food safety is linked.

\begin{tabular}{|c|c|c|c|c|c|c|}
\hline Question & Total & $\begin{array}{l}\text { Agriculture and } \\
\text { Natural } \\
\text { Resources }\end{array}$ & $\begin{array}{l}\text { Human Resource } \\
\text { and Development }\end{array}$ & $\begin{array}{c}\text { Engineering and } \\
\text { Technology }\end{array}$ & $\begin{array}{c}\text { Health } \\
\text { Sciences }\end{array}$ & $\begin{array}{l}\text { Pure and } \\
\text { Applied } \\
\text { Sciences }\end{array}$ \\
\hline Q1. What are microorganisms? & 92.4 & 92.3 & 93.2 & 95.8 & 90.9 & 89.8 \\
\hline Q2. How should chunks of raw meat be stored? & 71.1 & 69.2 & 81.4 & 87.3 & 84.8 & 77.3 \\
\hline $\begin{array}{l}\text { Q3. When is the best time to purchase frozen food } \\
\text { when shopping? }\end{array}$ & 68.1 & 74.4 & 62.3 & 60.6 & 72.7 & 70.5 \\
\hline $\begin{array}{l}\text { Q4. Of the following, which is the least safe way } \\
\text { to thaw raw meat? }\end{array}$ & 29.5 & 38.5 & 18.6 & 25.4 & 24.2 & 32.9 \\
\hline $\begin{array}{l}\text { Q5. What should be done if the leftovers are still } \\
\text { not eaten completely? }\end{array}$ & 24.6 & 20.5 & 32.2 & 28.2 & 15.2 & 23.9 \\
\hline $\begin{array}{l}\text { Q6. A refrigerator has three shelves, on which } \\
\text { shelf do you think raw meat should be placed? }\end{array}$ & 24 & 33.3 & 23.7 & 21.1 & 15.2 & 20.4 \\
\hline $\begin{array}{l}\text { Q7. What is the recommended temperature for } \\
\text { fridges? }\end{array}$ & 55 & 65.4 & 49.2 & 53.5 & 57.6 & 50.0 \\
\hline $\begin{array}{l}\text { Q8. To prevent food poisoning, how often should } \\
\text { the kitchen sink drain in your home be sanitized? }\end{array}$ & 62.6 & 66.7 & 67.8 & 62.0 & 54.5 & 59.1 \\
\hline $\begin{array}{l}\text { Q9. Which is the most hygienic way to wash your } \\
\text { hands? }\end{array}$ & 38.6 & 30.8 & 42.4 & 36.6 & 33.3 & 46.6 \\
\hline $\begin{array}{l}\text { Q10. If you have a wound on the back of your } \\
\text { hand, should you prepare food for other people? }\end{array}$ & 44.4 & 38.5 & 39.0 & 46.5 & 51.5 & 48.9 \\
\hline $\begin{array}{l}\text { Q11. Imagine that your electricity went off and the } \\
\text { meat, chicken, and/or seafood in your freezer } \\
\text { thawed and felt warm. To prevent food poisoning, } \\
\text { what should you do? }\end{array}$ & 7.3 & 3.8 & 3.4 & 12.7 & 3.0 & 10.2 \\
\hline $\begin{array}{l}\text { Q12. If a family member is going to be several } \\
\text { hours late for a hot meal, how should you store the } \\
\text { meal to keep it safe until this person is ready to eat } \\
\text { it? }\end{array}$ & 32.2 & 35.9 & 28.8 & 31.0 & 42.4 & 28.4 \\
\hline Mean correct responses & 46.2 & 47.4 & 45.2 & 46.7 & 45.4 & 46.5 \\
\hline
\end{tabular}

Despite the fact that the college of Health Sciences on average performed slightly better than other colleges (in scoring at least $50 \%$ in more food safety questions), it is also worth noting that it performed the worst in two questions compared to the rest of the colleges. These questions were 'A refrigerator has three shelves, on which shelf do you think raw meat should be placed?' and 'Imagine that your electricity went off and the meat, chicken, and/or seafood in your freezer thawed and felt warm. To prevent food poisoning, what should you do?', where the correct responses were $15.2 \%$ and $3 \%$ respectively. The observations made in this study based on summarized data in Table 3 is that there was no clear trend attributable to college and food safety knowledge of learners. Responses (right or wrong) differed with the question type and respondents' college category i.e. no category consistently answered questions better or worse than others. Therefore, when it comes to food safety education/training as a mitigation strategy, emphasis should be paid to all the categories of learners irrespective of which college they belong to. Further studies are also warranted to establish why some colleges such as Engineering and Technology, and Human Resource and Development outperformed the rest of the other colleges (Health Sciences, Agriculture and Natural Resources, and Pure and Applied Sciences) which were expected to be more knowledgeable in food safety knowledge in regard to some questions by virtue of the possibility of a number respondents in the latter categories being offered food safety related science courses.

\section{Overall food safety beliefs and attitudes of respondents}

Beliefs and attitudes are vital components of food safety that can either positively or negatively impact on practices and behaviors of food handlers with the potential of increasing or reducing foodborne disease incidences [32]. According to Al-Kandari et al. [33], attitude is an important link between knowledge grasp and practices as food safety handlers who have good food safety knowledge often interpret it into good food safety practices if they possess 
positive beliefs and attitudes, and contrariwise [34]. Figure 1 presents the proportion of JKUAT university students' response to food safety beliefs and attitudes statements. Generally, most respondents' food safety beliefs and attitudes seemed to positively support production, provision and consumption of safe food. Over $70 \%$ of respondents seemed to have positive beliefs and attitudes in most of the food safety beliefs and attitudes statements.

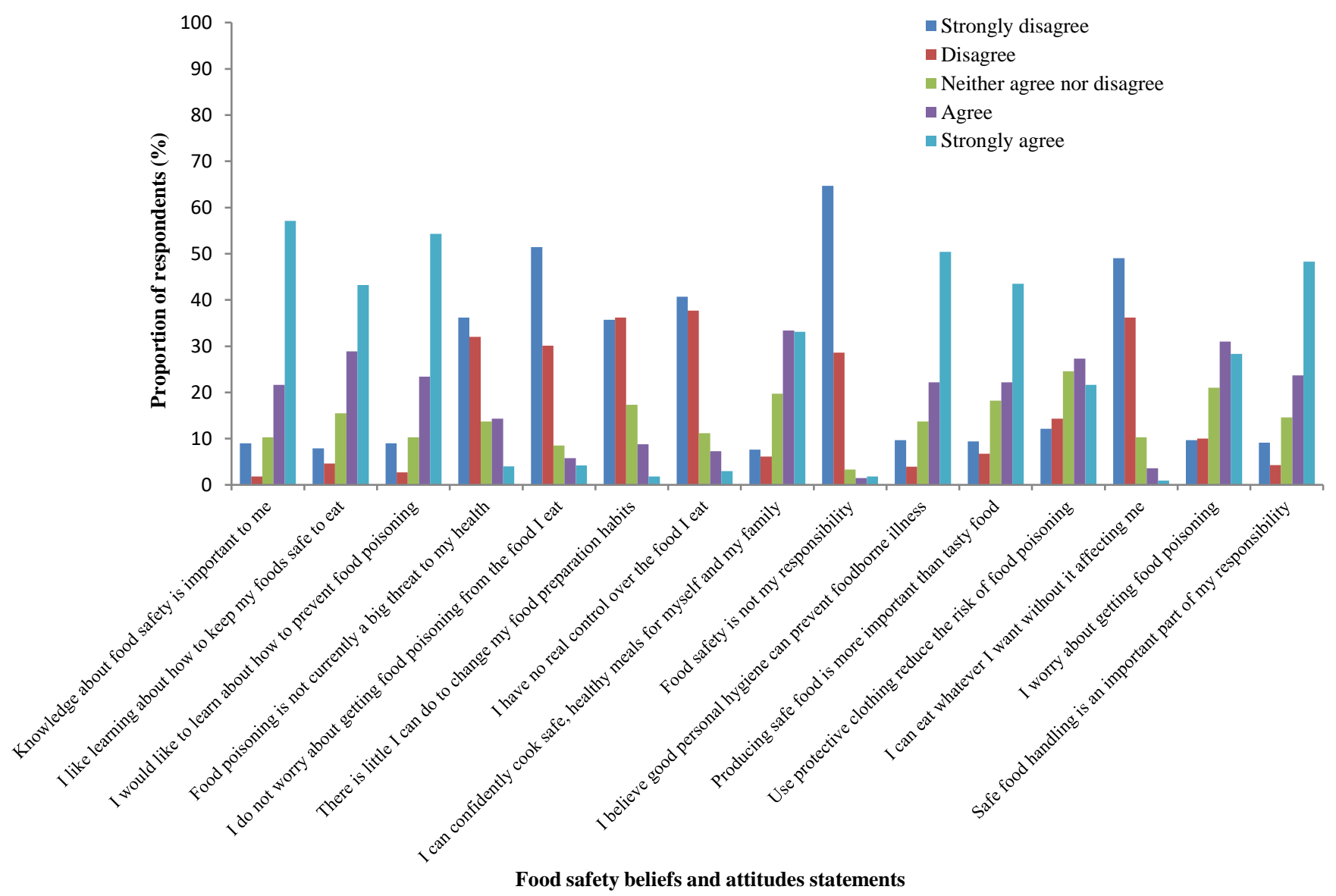

Fig. 1. Proportion of JKUAT university students responses to food safety beliefs and attitudes statements $(n=329)$.

A relatively large number of respondents $(78.7 \%)$ agreed or strongly agreed that food safety knowledge is important to them while $10.3 \%$ of them neither agreed nor disagreed. In a previous study assessing the food safety knowledge of University of Maine students, Ferk et al. [29] reported less than half of the respondents (43\%) feeling that food safety was important to them while in a study investigating food safety knowledge and hygiene practices among veterinary medicine students at Trakia University in Bulgaria reported that $95 \%$ of respondents felt that food safety knowledge was vital to them [22]. A study by Al-Kandari et al. [33] who were investigating food safety knowledge, attitudes and practices of food handlers in restaurants in Kuwait reported $65 \%$ of respondents strongly agreeing that food safety knowledge was important. The dissimilarities in these findings may be attributed to differences in the study populations in terms of previous trainings, experiences and study settings e.g. Al-Kandari et al. [33] study was on restaurant food handlers while that of Stratev et al. [22] was carried out on university veterinary medicine students only. Generally, one would expect a higher proportion of the sampled population to express the importance of food safety knowledge. Food safety knowledge is important in order to make the correct, well informed decisions in regard to safe food preparation/handling, storage and consumption with the aim of preventing foodborne illnesses. The majority of respondents' acceptance that food safety knowledge was important to them may suggest their good attitudes and practices in safe food handling. Abdul-Mutalib et al. [35] opined that food handlers possessing good food safety knowledge are more likely to have good food safety attitudes and practices.

Likewise, $72.1 \%$ and $77.7 \%$ of the respondents were willing to learn how to make their food safe to eat, and how to prevent food poisoning from occurring respectively. This observation is tied to the willingness to acquire food safety knowledge. It is generally accepted that food poisoning is a big challenge to human health in addition to affecting food and nutrition security. Less than a quarter of the respondents $(18.3 \%)$ felt that food poisoning is not a big threat to their health. This proportion of the respondents may be a threat to food safety as such belief may lead to food contamination and spread of foodborne diseases. On the contrary, $68.2 \%$ of the respondents felt that it was a threat while $13.7 \%$ neither agreed nor disagreed with the statement. In fact, $81.1 \%$ of the survey participants were worried of getting food poisoning which is probably why a relatively small number of the respondents $(4.5 \%)$ felt that they could eat whatever they wanted without it affecting them, while, on the contrary, $85.2 \%$ of the respondents thought otherwise. 
Change of poor food handling habits is one of the numerous ways of ensuring food safety. A small number of respondents $(10.6 \%)$ felt that there was little they could do to change their food preparation habits while $71.9 \%$ thought otherwise. A $10.3 \%$ of the respondents felt that they had no control over the food they ate while $78.4 \%$ thought to the contrary. A tiny proportion of the respondents (3.3\%) reported that food safety was not their responsibility while an impressive $93.3 \%$ thought on the contrary with the remaining proportion (3.4\%) neither agreeing nor disagreeing with the statement. This is an encouraging observation from the learners as this may mean that majority of them are embracing the responsibility of ensuring that the food they handle and/or consume is safe. The study revealed that slightly less than half of respondents $(48.9 \%)$ felt that use of protective clothing (caps, masks, protective gloves and adequate clothing) could reduce the risk of food poisoning with the rest of respondents either disagreeing or neither agreeing nor disagreeing with the statement. Use of protective clothing is important to prevent food contamination and spread of foodborne diseases. This result shows that majority of the respondents had poor food safety belief in this aspect. Al-Kandari et al. [33] study reported $72.9 \%$ of the respondents agreeing that use of protective clothing is important in ensuring food safety while that of Faour-Klingbeil et al. [36] reported $96.2 \%$ of respondents reporting that use of protective clothing is important in ensuring food safety. There is a clear difference between this study's findings and these two other research reports. This difference may be attributed to the fact that these two studies were carried out on food handlers in food business establishments while this study was carried out on students some of whom had reported that they rarely cooked for themselves suggesting limited knowledge and practices in safe food handling, which may have influenced their beliefs and attitudes. On the other hand, it is expected that handlers in a business kind of environment receive some form of safe food handling training which can positively influence their beliefs and practices.

Good personal hygiene is generally regarded as one of the best ways of preventing food contamination and spread of foodborne illnesses. In this study, $72.6 \%$ of the respondents agreed or strongly agreed with the statement that good personal hygiene can prevent foodborne illness while $13.6 \%$ of the respondents disagreed with it. The remaining proportion, $13.8 \%$ neither agreed nor disagreed. Most of the foodborne diseases are linked to poor personal hygiene practices of the food handlers especially in food businesses. Slightly over a quarter of the respondents (28\%) either thought that safe food handling was not an important part of their responsibility or were indecisive. This is a dangerous belief because food safety is everyone's responsibility from the point of production to the point of consumption, end of farm-to-form continuum (where the consumers, in this case, the respondents are responsible).

\section{E. Responses on food safety beliefs and attitudes of the five college categories}

Out of the five colleges, learners in Pure and Applied Sciences constituted the majority $(86.4 \%)$ of those who agreed or strongly agreed that the knowledge of food safety was important to them, followed by students in Health Sciences (84.8\%), Engineering and Technology (80.3\%), Agriculture and Natural Resources $(74.4 \%)$ and Human Resource and Development (67.8\%) respectively (Table 4). A part from students in Human Resource and Development, and Engineering, at least $70 \%$ of those from other colleges agreed or strongly agreed to like to learn about how to keep their foods safe to eat with the majority of the students coming from Health Sciences $(84.8 \%)$ followed by Pure and Applied Sciences (82.9\%). Learners from Human Resource and Development had the least proportion (57.6\%) of those who agreed or strongly agreed to like to learn about how to keep their foods safe to eat. There appears to be some consistency among the learning categories (colleges) in regard to these two attitude statements where those who felt that food safety was important to them also agreeing to the fact that they would like to learn how to keep their foods safe in almost similar proportions. From this observation, it can be hypothesized that persons who are more concerned about food safety are also more willing to learn how to continue making sure that food is safe to eat.

To the following statements; 'I do not worry about getting food poisoning from the food I eat', 'There is little I can do to change my food preparation habits', 'I have no real control over the food I eat' and 'Food safety is not my responsibility', generally, students in the Engineering and Technology category had the highest proportion of learners agreeing or strongly agreeing to the statements although the proportion was not more than $15 \%$ for any of the statements. There was no clear trend observed in responding to these statements across the five colleges. Learners in the Engineering and Technology category had the largest proportion of respondents (between $57.7 \%$ and $80.3 \%$ ) agreeing or strongly agreeing to the following food safety beliefs and attitudes statements generally; 'I believe good personal hygiene can prevent foodborne illness', 'Using caps, masks, protective gloves and adequate clothing reduce the risk of food poisoning' and 'Safe food handling is an important part of my responsibility'. Those from Human Resource and Development, compared to other categories, agreed or strongly agreed with the statements the least. Just like in previous observations, there is no clear trend observed in responding to these statements across the five student categories (colleges). Worth noting however, is that only close to a third (32.2\%) of Human Resource and Development category of learners agreed or strongly agreed that using caps, masks, protective gloves and adequate clothing reduce the risk of food poisoning while the rest of the categories slightly exceeded $50 \%$. More investigations are warranted to find out why this is the case. 


\begin{tabular}{|c|c|c|c|c|c|c|}
\hline Statement & Total & $\begin{array}{c}\text { Agriculture and } \\
\text { Natural } \\
\text { Resources }\end{array}$ & $\begin{array}{c}\text { Human } \\
\text { Resource and } \\
\text { Development }\end{array}$ & $\begin{array}{c}\text { Engineering } \\
\text { and } \\
\text { Technology }\end{array}$ & $\begin{array}{l}\text { Health } \\
\text { Sciences }\end{array}$ & $\begin{array}{l}\text { Pure and } \\
\text { Applied } \\
\text { Sciences }\end{array}$ \\
\hline \multicolumn{7}{|c|}{ Knowledge about food safety is important to me } \\
\hline Strongly disagree & 9.1 & 11.5 & 13.5 & 7.0 & 12.1 & 6.8 \\
\hline Disagree & 1.8 & 0 & 5.1 & 1.4 & 0 & 0 \\
\hline Neither agree nor disagree & 10.3 & 14.1 & 13.5 & 11.3 & 3.0 & 6.8 \\
\hline \multicolumn{7}{|c|}{ I like learning about how to keep my foods safe to eat } \\
\hline Strongly disagree & 7.9 & 3.8 & 15.2 & 2.8 & 12.1 & 4.5 \\
\hline Disagree & 4.5 & 0 & 5.1 & 9.8 & 0 & 3.4 \\
\hline Neither agree nor disagree & 15.5 & 16.7 & 22.0 & 22.5 & 3.0 & 9.1 \\
\hline Agree & 28.9 & 28.2 & 27.1 & 26.8 & 39.4 & 28.4 \\
\hline Neither agree nor disagree & 8.5 & 3.8 & 13.5 & 12.7 & 9.1 & 5.7 \\
\hline Agree & 5.8 & 3.8 & 8.5 & 8.4 & 6.1 & 3.4 \\
\hline Strongly agree & 4.2 & 5.1 & 3.4 & 5.6 & 0 & 4.5 \\
\hline \multicolumn{7}{|c|}{ There is little I can do to change my food preparation habits } \\
\hline Strongly disagree & 35.9 & 41.0 & 28.8 & 32.4 & 27.3 & 42.0 \\
\hline Disagree & 36.2 & 34.6 & 44.1 & 35.2 & 36.4 & 32.9 \\
\hline Neither agree nor disagree & 17.3 & 14.1 & 22.0 & 21.1 & 21.2 & 12.5 \\
\hline Agree & 8.8 & 7.7 & 1.7 & 9.8 & 15.1 & 11.4 \\
\hline Strongly agree & 1.8 & 2.6 & 3.4 & 1.4 & 0 & 1.1 \\
\hline \multicolumn{7}{|c|}{ I have no real control over the food I eat } \\
\hline Strongly disagree & 40.7 & 44.9 & 42.4 & 32.4 & 24.2 & 50.0 \\
\hline Disagree & 37.7 & 33.3 & 42.4 & 40.8 & 48.5 & 31.8 \\
\hline Agree & 1.5 & 1.3 & 1.7 & 1.4 & 3.0 & 1.1 \\
\hline Strongly agree & 1.8 & 0 & 0 & 1.4 & 3.0 & 0 \\
\hline \multicolumn{7}{|c|}{ I believe good personal hygiene can prevent foodborne illness } \\
\hline Strongly disagree & 9.7 & 11.5 & 11.9 & 7.0 & 12.1 & 7.9 \\
\hline Disagree & 3.9 & 3.8 & 3.4 & 4.2 & 6.1 & 3.4 \\
\hline Neither agree nor disagree & 13.7 & 16.7 & 20.3 & 15.5 & 12.1 & 5.7 \\
\hline Agree & 22.2 & 23.1 & 18.6 & 28.2 & 18.2 & 20.4 \\
\hline Strongly agree & 50.4 & 44.9 & 45.8 & 41.0 & 51.5 & 62.5 \\
\hline \multicolumn{7}{|c|}{ Using caps, masks, protective gloves and adequate clothing reduce the risk of food poisoning } \\
\hline Strongly disagree & 12.1 & 19.2 & 13.5 & 8.4 & 9.1 & 9.1 \\
\hline Disagree & 14.3 & 12.8 & 20.3 & 14.1 & 15.1 & 11.4 \\
\hline Neither agree nor disagree & 24.6 & 20.5 & 33.9 & 19.7 & 21.2 & 27.3 \\
\hline Agree & 27.3 & 24.3 & 23.7 & 39.4 & 30.3 & 21.6 \\
\hline Strongly agree & 21.6 & 23.1 & 8.5 & 18.3 & 24.2 & 30.7 \\
\hline \multicolumn{7}{|c|}{ Safe food handling is an important part of my responsibility } \\
\hline Strongly disagree & 9.1 & 11.5 & 13.5 & 7.0 & 9.1 & 5.7 \\
\hline Disagree & 4.2 & 2.6 & 6.8 & 2.8 & 6.1 & 4.5 \\
\hline Neither agree nor disagree & 14.6 & 16.7 & 23.7 & 9.8 & 15.1 & 10.2 \\
\hline Agree & 23.7 & 19.2 & 23.7 & 33.8 & 27.3 & 18.2 \\
\hline Strongly agree & 48.3 & 50.0 & 32.2 & 46.5 & 42.4 & 61.4 \\
\hline
\end{tabular}

\section{CONCLUSION}

Although there was a limited number of respondents in relation to the student total population, this study has provided an insight in regard to food safety knowledge, beliefs and attitudes among learners that can form the basis for further studies. The students who participated in this study generally had unsatisfactory food safety knowledge especially in regard to cross-contamination and temperature control/food preservation. No respondent/learner category (Agriculture and Natural Resources, Engineering and Technology, Health Sciences, Pure and Applied Sciences and, Human Resource and Development) consistently gave correct or wrong responses to food safety and knowledge questions. Therefore, training or education in food safety to improve knowledge and practices need to include all learner categories and ought not to only focus on theory but the practical aspects as well. The learners seemed to generally have positive food safety beliefs and attitudes which supports good food safety practices. This is bound to improve further when the food safety knowledge gap is addressed through a systematically well designed and delivered training/education in good food safety practices.

\section{ACKNOWLEDGMENT}

The author would like to acknowledge all respondents who agreed to participate in this study. 


\section{REFERENCES}

[1] Linscott, A. J. (2011). Food-borne illnesses. Clinical Microbiology Newsletter, 33, 41-45. https://doi.org/10.1016/j.clinmicnews.2011.02.004.

[2] Imathiu, S.M. (2017). Street vended foods: Potential for improving food and nutrition security or a risk factor for foodborne diseases in developing countries? Current Research in Nutrition and Food Science, 5, 55-65. http://dx.doi.org/10.12944/CRNFSJ.5.2.02.

[3] Al-Shabib, N.A., Husain, F.M., \& Khan, J.M. (2017). Study on food safety concerns, knowledge and practices among university students in Saudi Arabia. Food Control, 73, 202-208. https://doi.org/10.1016/j.foodcont.2016.08.00.

[4] WHO. (2003). Food safety issues: Gems/food regional diets (pp. 127). World Health Organization.

[5] Redmond, E. C., \& Griffith, C. J. (2003a). Consumer food handling in the home: a review of food safety studies. Journal of Food Protection, 66, 130-161. https://doi.org/10.4315/0362-028X-66.1.130.

[6] Knabel, S. J. (1995). Foodborne illness: Role of home food handling practices (scientific status summary). Food Technology, 49, 119-131.

[7] Redmond, E. C. \& Griffith, C. J. (2003b). A comparison and evaluation of research methods used in consumer food safety studies. International Journal of Consumer studies, 27, 17-33. https://doi.org/10.1046/j.1470-6431.2003.00283.x.

[8] European Food Safety Authority (EFSA), (2011). The European Union summary report on trends and sources of zoonoses, zoonotic agents and food-borne outbreaks in 2009. Scientific report of EFSA and ECDC European. Food Safety Authority Journal, 9, 287.

[9] Gong, S., Wang, X., Yang, Y., \& Bai, L. (2016). Knowledge of food safety and handling in households: A survey of food handlers in Mainland China. Food Control, 64, 45-53. https://doi.org/10.1016/j.foodcont.2015.12.006.

[10] Courtney, S.M., Majowicz1, S.E. \& Dubin, J.A. (2016). Food safety knowledge of undergraduate students at a Canadian university: results of an online survey. BMC Public Health, 16, 1-16. doi: 10.1186/s12889-016-3818-y.

[11] Byrd-BredBenner, C., Maurer, J., Wheatley, V., Schaffner, D., Bruhn, C., \& Blalock, L. (2007). Food safety self-reported behaviors and cognitions of young adults: results of a national study. Journal of Food Protection, 70, 1917-26. doi: 10.4315/0362-028x-70.8.1917.

[12] Majowicz, S.E., Diplock, K.J., Leatherdale, S.T., Bredin, C.T., Rebellato, S., Hammond, D., Jones-Bitton, A. \& Dubin, J.A. (2015). Food safety knowledge, attitudes and self-reported practices among Ontario high school students. Canadian Journal of Public Health, 106, 520-526. doi: 10.17269/cjph.106.5213.

[13] Altekruse, S., Street D., Fein, S., \& Levy, A. (1996). Consumer knowledge of foodborne microbial hazards and food-handling practices. Journal of Food Protection, 59, 287-94. doi: 10.4315/0362028x-59.3.287.

[14] Slater, J. (2013). Is cooking dead? The state of home economics food and nutrition education in a Canadian province. International Journal of Consumer Studies, 37, 617-24. https://doi.org/10.1111/ijcs.12042.

[15] Fein, S.B., Lando, A.M., Levy, A.S., Teis, M.F., \& Noblet, C. (2011) Trends in U.S. consumers' safe handling and consumption of food and their risk perceptions, 1988 through 2010. Journal of Food Protection, 74, 1513-23. doi: 10.4315/0362-028X.JFP-11-017.

[16] Fischer, A.R.H., \& Frewer, L.J. (2008). Food-safety practices in the domestic kitchen: demographic, personality, and experimental determinants. Journal of Applied Psychology, 38, 2859-84. https://doi.org/10.1111/j.1559-1816.2008.00416.x.

[17] Sharif, L. \& Al-Malki, T. (2010). Knowledge, attitude and practice of Taif University students on food poisoning. Food Control, 21, 55-60. doi:10.1016/j.foodcont.2009.03.015.

[18] Green, E.J., \& Knechtges, P.L. (2015). Food safety knowledge and practices of young adults. Journal of Environmental Health, 77, 1824.

[19] Hassan, H.F., \& Dimassi, H. (2014). Food safety and handling knowledge and practices of Lebanese university students. Food Control, 40, 127-133. https://doi.org/10.1016/j.foodcont.2013.11.040.

[20] Jevsnik, M., Hlebec, V., \& Raspor, P. (2008). Consumers' awareness of food safety from shopping to eating. Food Control, 19, 737-745. https://doi.org/10.1016/j.foodcont.2007.07.017.

[21] Nesbitt, A., Majowicz, S., Finley, R., Marshall, B., Pollari, F., Sargeant, J., et al. (2009). High-risk food consumption and food safety practices in a Canadian community. Journal of Food Protection, 72, 2575-86. doi: 10.4315/0362-028x-72.12.2575.

[22] Stratev, D., Odeyemi, O.A., Pavlov, A., Kyuchukova, R., Fatehi, F. \& Bamidele, F.A. (2017). Food safety knowledge and hygiene practices among veterinarymedicine students at Trakia University, Bulgaria.
Journal of Infection and Public Health, 10, 778-782. https://doi.org/10.1016/j.jiph.2016.12.001.

[23] Takeda, S., Akamatsu, R., Horiguchi, I. \& Marui, E. (2011) Relationship among food-safety knowledge, beliefs, and riskreduction behavior in university students in Japan. Journal of Nutrition and Education Behavior, 43, 449-54. https://doi.org/10.1016/j.jneb.2010.08.009.

[24] Ovca, A., Jev`snik, M. \& Raspor, P. (2014). Food safety awareness, knowledge and practices among students in Slovenia. Food Control, 42,144-51. https://doi.org/10.1016/j.foodcont.2014.01.036.

[25] Lazou, T., Georgiadis, M., Pentieva, K., McKevitt, A., Iossifidou, E. (2012). Food safety knowledge and food-handling practices of Greek university students: a questionnaire-based survey. Food Control, 28, 400-11. https://doi.org/10.1016/j.foodcont.2012.05.027.

[26] Osaili, T., Obeidat, B.A., Jamous, D.O.A., Bawadi, H.A. (2011). Food safety knowledge and practices among college female students in north of Jordan. Food Control, 22, 269-276 https://doi.org/10.1016/j.foodcont.2010.07.009.

[27] Marklindera, I., Ahlgren, R., Blucher, A., Borjessond, S.E. Hellkvista, F., Moazzamie, M., Schelinf, J., Zetterstroma, E. Eskhultg, G. \& Danielsson-Thamh, M. (2020). Food safety knowledge, sources thereof and self-reported behaviour among university students in Sweden. Food Control, 113 https://doi.org/10.1016/j.foodcont.2020.107130.

[28] USDA (2011). Safe Food Handling: "Danger Zone" (40 ${ }^{\circ} \mathrm{F}-140$ ${ }^{\circ}$ F). U.S. Department of Agriculture. USDA - FSIS Web Site. Available http://www.fsis.usda.gov/wps/portal/fsis/topics/foodsafetyeducation/get-answers/food-safety-fact-sheets/safe-foodhandling/danger-zone-40-f-140-f/ct_index. Accessed July 10, 2020

[29] Ferk, C.C., Calder, B.L. \& Camire, M.E. (2016). Assessing the food safety knowledge of university of Maine students. Journal of Food Science and Education, 15, 14-22. https://doi.org/10.1111/1541 4329.12076.

[30] Prater, K.J., Fortuna, C.A., McGill, J.L., Brandeberry, M.S., Stone, A.R. \& Lu, X. (2016). Poor hand hygiene by college students linked to more occurrences of infectious diseases, medical visits, and absence from class. American Journal of Infection Control, 44, 66-70 doi: 10.1016/j.ajic.2015.08.012.

[31] Luo, X., Xu, X., Chen, H., Bai, R., Yan Zhang, Y., Xiaorong-Hou, X., Zhanga, F., Zhang, F., Sharma, M., Zeng, H. \& Zhao, Y. (2019) Food safety related knowledge, attitudes, and practices (KAP) among the students from nursing, education and medical college in Chongqing, China. Food Control, 95, 181-188. https://doi.org/10.1016/j.foodcont.2018.07.042.

[32] Sani, N.A. \& Siow, O.N. (2014). Knowledge, attitudes and practices of food handlers on food safety in food service operations at the Universiti Kebangsaan Malaysia. Food Control, 37, 210-217. https://doi.org/10.1016/j.foodcont.2013.09.036.

[33] Al-Kandari, D., Al-abdeen, J. and Sidhu, J. 2019. Food safety knowledge, attitudes and practices of food handlers in restaurants in Kuwait. Food Control, 102, 103-110. https://doi.org/10.1016/j.foodcont.2019.03.040.

[34] Zanin, L. M., Cunha, D. T., Rosso, V. V., Capriles, V. D., \& Stedefeldt, E. (2017). Knowledge, attitudes and practices of food handlers in food safety: An integrative review. Food Research International,

100

$53-62$ https://doi.org/10.1016/j.foodres.2017.07.042

[35] Abdul-Mutalib, N., Syafinaz, A., Sakai, K., \& Sharai, Y. (2015). An overview of foodborne illness and food safety in Malaysia. International Food Research Journal, 22, 896-901.

[36] Faour-Klingbeil, D., Kuri, V., \& Todd, E. (2015). Investigating a link of two different types of food business management to the food safety knowledge, attitudes and practices of food handlers in Beirut, Lebanon. Food Control, 55, 166-175. https://doi.org/10.1016/j.foodcont.2015.02.045. 